\title{
When is normative recruitment legitimate?
}

\author{
Lars Oystein Ursin and Berge Solberg
}

Rosamond Rhodes and John Harris have both recently argued that we all have a general moral duty to participate in medical research. However, neither Rhodes' nor Harris' arguments in support of this obligation stand up to scrutiny, and severe and convincing criticism has been levelled against their case. Still, to refute their arguments is not to refute the conclusion. There seems to be some truth in the view that when people are asked to take part in medical research, their choice is not completely morally neutral. In this article, we argue that the proper question to ask is when, rather than if, a certain moral duty to volunteer for medical research can be appealed to. To answer this question, we need a denser description of relevant research projects and their context rather than just describing medical research in general. Drawing on our study of participants in the Norwegian HUNT biobank, we use the normative implications of the Norwegian concept «dugnad» as an analogy to discuss the requirement of providing neutral information to potential biobank participants in order to promote their free and informed decision as to whether or not to take part. We suggest that normative recruitment is not just a question of principles and ethics. It is also a question of research design and the creation of the common good in the community where the research takes place.

Keywords: autonomy, biobanking, dugnad, normative recruitment, research ethics

\section{A general duty to participate in medical research}

In an attempt to interpret anew the autonomy and obligations of participants in biobank research, Rosamond Rhodes makes a frontal attack on contemporary research ethics in her article 'Rethinking research ethics' 
(Rhodes 2005: 7). According to Rhodes, in bioethical literature, informed consent is argued for on the basis of an ambiguous concept of autonomy. On the one hand, autonomy is taken as an ideal for the individual. The ideal, then, is that the foundation for an individual's choice is freedom and reflection. On the other hand, autonomy is taken to be a norm for how an individual's choices are to be understood.

While such a norm demands an assumption that an individual makes autonomous choices, according to Rhodes the opposite position is prevalent in bioethics literature. The norm of autonomy is replaced by the ideal, which drastically restricts the kinds of people who can truly be said to be autonomous. In this manner, the kinds of people who are genuinely autonomous, able to give an informed consent and to take part in research, are separated from those who do not possess these qualities, and who are consequently excluded from research.

Rhodes accentuates autonomy as a social norm, and argues against the exclusion of groups of people as participants in research on the basis of an ideal of autonomy. Indeed, everybody should take part in research, Rhodes argues, because the vulnerable aspect in this context is the future patient rather than the present research participant. Further, to assume that it is against the will and interests of people to take part in a morally laudable and other-regarding project, such as improving medicine through research, is for Rhodes deeply disrespectful (Rhodes 2005: 14). She states the implication of her views on autonomy, regarding research participation thus: «So, in light of our appreciation of human vulnerability to injury and disease and our appreciation of the value of clinical research, reasonable people should endorse policies that make research participation a social duty» (Rhodes 2005:15).

On the basis of these considerations, Rhodes puts forward a novel proposal: her idea is that society, after thorough deliberation, should institute obligatory participation in medical research at regular intervals for all citizens. The choice is then not if one wants to participate in a study or not, but which study to participate in. All studies would have to be approved by public medical authorities. This would draw attention to the approval process and would require full disclosure of the study design in order for institutions to be judged trustworthy by prospective participants. Projects should also be deemed of high quality and importance, and with few or no inexpedient burdens placed on participants. The granting of informed consent in this context would be part of the active exercise of one's autonomy, inside a field restricted by law.

Rhodes aims to establish medical research as one of society's central tasks. From this perspective, it follows that the demand that all research should be of direct benefit to participants undermines its social and longterm purposes. In the regulation and evaluation of specific research pro- 
jects, it is important to focus on the quality of the research, and to maintain legitimate trust on the part of participants. By making autonomy and participation the norm, the default position for Rhodes is that everybody can and will contribute to the common good resulting from medical research.

Sarah Chan and John Harris shares Rhodes' view of the default position. They do not, however, think that this justifies conscription of participants to medical research (Chan \& Harris 2008: 11). Harris likewise discusses in the article 'Scientific research is a moral duty' the question of a putative duty to participate in research as a moral question, and not a juridical or a political one (Harris 2005). In this article he emphasises two principles, both of which he thinks commit us to a moral obligation to participate in medical research. The first principle is our moral duty not to harm others. Harris argues that such harm is the consequence of declining to contribute to this kind of research. The second principle is the principle of justice, which results in the problem of the freerider.

Harris does not argue for any legal duty to take part in research, but holds that these principles make it ethically problematic to refuse participation. To participate is required, both to contribute to the common good and to be able to respect oneself as a moral actor. On this basis, it is possible to presume that a safeguarded participation also would be in the interests of those deemed to be without full competence to consent. Harris concludes: "There is then a moral obligation to participate in research in certain contexts. This will obviously include minimally invasive and minimally risky procedures such as participation in biobanks, provided safeguards against wrongful use are in place» (Harris 2005: 247).

\section{Perfect and imperfect duties}

Although the views put forward by Rhodes and Harris touch upon something important, their arguments are far from unproblematic, as shown by the debate and criticism sparked by their articles. ${ }^{1}$ John Harris argues, for instance, that to choose not to participate in medical research conflicts with the principle of fairness. Non-participants are illegitimate freeriders if they later benefit from the research by receiving improved health care. In making this argument, however, Harris overlooks the fact that even non-participants pay for the health care they receive through taxation or insurance premiums, and that they also have no choice but to benefit from researchbased health care. Furthermore, it can be argued that one of the benefits of modern society is precisely a kind of institutionalised freeriding in the form of division of labour. This makes it unnecessary (and unfeasible) for everybody to take part in any kind of research from which we might possibly benefit. $^{2}$ 
A similar kind of objection has been made to Harris's use of the principle of a duty to help others by taking part in medical research (Brassington 2007; Sharpsay \& Pimple 2007). Sharpsay and Pimple invoke the Kantian notion of imperfect moral duties as the most precise way to describe the relevant obligation here: "participation in medical research per se is not morally obligatory, but neither is it supererogatory; it is one way in which people may choose to discharge their imperfect obligation to help others.» (Sharpsay \& Pimple 2007) A perfect moral obligation always to help others would make our lives unmanageable, as we are finite beings with limited means. Furthermore, because participating in medical research is only one of many ways to help others in need, it can at most be argued to be an imperfect obligation to take part. ${ }^{3}$

For Rhodes, consenting to take part in medical research is to contribute to the common good. The debate on informed consent for, or a compulsory participation in, medical research, must therefore take place in the context of a common understanding of the common good. However, in a pluralistic and liberal society, such a consensus is not necessarily reached, or even aimed at (London 2005; Sharp \& Yarborough 2005). Different answers will be obtained for questions such as: What are the merits of good health? What constitutes good health? Do biobank research and other medical research promote public health in the right way?

Rhodes's system of mandatory research participation entails a limited obligation to take part in research projects. Even such a limited obligation is, however, hard to uphold. As argued by Robert Wachbroit and David Wasserman,

[R]esearch participation should be seen as a valuable civic activity, like school tutoring, volunteer fire-fighting, and neighbourhood patrolling. Like those other activities, it is a way for individuals to serve a community from which they derive many benefits. It should be encouraged and praised like those other activities, but there is no reason to single it out as the subject of a universal duty. (Wachbroit \& Wasserman 2005: 48-49)

This line of argument removes medical research from the prominent position that compels Rhodes and Harris to see it as subject to a duty to take part. For both Rhodes and Harris, the prominent position of medical research establishes a duty to take part based on intergenerational fairness: we have an obligation not only to maintain the present level of medical care but also to improve it through research for the sake of future generations, just as preceding generations by their research participation have made the present level of medical care possible.

Such an imperative to undertake research should stem from the moral obligation we have to help alleviate the suffering of today and tomorrow. However, for the research imperative to be a moral obligation, i.e. somet- 
hing we must do, failure to carry out medical research must not only harm people, it must also be indispensable in avoiding (future) harm. However, in his book What price better health? Daniel Callahan questions both of these assumptions. In countering the argument that more medical research is indispensable in avoiding (future) harm, Callahan reminds us that helping others by participating in medical research is only one aspect of our vision of a good society. The provision of social security, proper education, family welfare, and so forth - along with improving health care - is a necessary, but not sufficient condition for fulfilling this vision. It is also important not to mistake social and cultural problems for medical problems.

Callahan does not accept the assumption that we have a duty to develop more effective medical treatments for future generations. In support of his view, he quotes Hans Jonas:

The destination of research is essentially melioristic [The belief that improvement of society depends on human effort.]. It does not serve the preservation of the existing good from which I profit myself and to which I am obligated. Unless the present state is intolerable, the melioristic goal is in a sense gratuitous, and this not only from the vantage point of the present. (Callahan 2003)

Callahan, like Sharpsay and Pimple, thus classifies medical research as an imperfect moral duty.

\section{The dugnad concept}

The questions of both intergenerational and intragenerational justice are, however, pertinent in the promotion of medical progress, unless one dismisses any duty to contribute to such progress, as Callahan does. Further, in opposition to Callahan, Rhodes aims to make medical research a common good that is part of a larger social contract.

Another way of thinking about this is that such an understanding can be created for every research project. It is the research project - through its design, context and intention - that has to construct and establish the common good, in order to justify normative recruitment. In the following, we will explore this idea by taking a closer look at a specific medical research project and a particular way of describing participation in the project. This exploration aims to make possible a more nuanced view of the way in which participation in medical research should be taken to be a perfect or an imperfect duty - or no duty at all. Thereafter, the implications of the answer to this question regarding the recruitment of participants will be pursued.

The Norwegian health study and biobank research project $\mathrm{HUNT}^{4}$ is referred to by policymakers as the largest health dugnad in Norway - or even in the world. ${ }^{5}$ HUNT is one of the largest existing projects in genetic 
epidemiology in the world. Yet what does the Norwegian word dugnad mean, and how does it relate to participation in health surveys and biobank research?

The dugnad concept stems historically from pre-industrial Norwegian farm regions. In these regions, the farms were rather small, the produce was consumed by the farming people themselves, and the market for goods and labour was limited. To undertake tasks such as roofing and haymaking, which were uncomplicated tasks but required a great deal of labour over a short time, farmers had to rely on a circle of neighbours to take turns in helping them. This kind of work was unpaid, but the farmer who benefited from the work was expected to treat the people who came to help by serving good food and beverages on the day of the dugnad, and maybe even to host a party for his workers.

According to a standard definition, «dugnad refers to when the neighbours of a farmer gather at his farm to help him to accomplish a large task, without being paid» (Østberg 1926). The traditional dugnad concept excluded communal and legal duties, and singled out the kind of informal duties that involved taking turns in helping one another. The dugnad institution relied on a mutual understanding of reciprocity between farmers who were equal in economic terms and the «relation of reciprocity comprised of generations» (Norddølum 1976; 1980).

New technology, increased trade and social differentiation led to the disappearance of the structural conditions for the traditional dugnad system in Norway in the first half of the 20th century (Klepp 2001: 84). The dugnad concept, however, has survived and is still widely in use in Norway (Klepp 1982: 92; Norddølum 1976: 72f). Today, the activities that come under the heading of dugnad are different from the original dugnad work, but share certain aspects of the «good old» dugnad or maybe just the «dugnad spirit».

From an international perspective, the Finnish concept of «talkoot», and the American concepts of a «bee» or «barn raising», both have a similar meaning to the Norwegian concept of the dugnad. The authors of this article learned this from the entry for dugnad in the Norwegian version of Wikipedia - an international project ${ }^{6}$ which might be termed «the largest dugnad ever», not in the sense of a system of reciprocity, but in the sense of making people contribute to the common good motivated by personal pride and solidarity without any economic gain. The Wikipedia project illustrates that invoking the «dugnad spirit» can be used to motivate and describe phenomena worldwide.

The dugnad spirit denotes that the values of liberty, equality and fraternity are actively promoted by a group and its members in freely committing themselves to work together as equals for the benefit of all. Today, dugnad is first and foremost associated with volunteering to do unpaid work for the common good. To be able to term something a dugnad, and to take part in 
a dugnad, is to make the activity morally praiseworthy. The dugnad spirit is then seen as a manifestation of an unselfish attitude that runs counter to a disintegrating society based on purely contractual relationships, and emphasises a spontaneous solidarity that is seen as both a moral ideal and the glue of society.

To benefit from or to take part in a dugnad should be motivated by a shared and acquired social conscience rather than by calculations of profit or from fear of sanctions. Helge Norddølum gives an example of an exploitation of the dugnad institution when a wealthy farmer in the Norwegian county of Valdres arranged a dugnad to build a mountain hotel (Norddølum 1976: 72f). The dugnad principle of reciprocity was thereby violated, as the hotel owners obviously did not, nor would not, help participants build their own hotels. The dugnad spirit of solidarity was also illegitimately invoked, as these hotels were built by unpaid workers in order to profit the owners. The obligations associated with an economy of mutual dependence were taken advantage of by entrepreneurs operating in a market economy system. Nonetheless, as the example of the Icelandic commercial biobank project deCODE ${ }^{7}$ shows, invoking a kind of dugnad spirit does not exclude economic profit from the dugnad result, if it is seen as beneficial for the community in which people regard themselves as belonging to.

In this article we discuss the dugnad model in relation to recruitment to biobank research. The salient features of the model is the equality of the participants, an element of non-economic personal interest or gain in taking part, a system of reciprocity, the invocation of civic duties and communal solidarity, and the pursuit of a common good - including communal prosperity. In addition, the tasks of a dugnad should not to be complicated or risky in such a way that places undue burdens on the participants. The tasks and outcomes of the dugnad should not be controversial. Only if it is reasonable to expect everybody to be able to attend, and have no moral qualms about participating, is it possible to blame people for not showing up.

The dugnad model invites a description of both the motivation and justification for biobank recruitment that is more nuanced and integrated than just pointing to aspects such as ethical or legal obligations, altruism and gift donation, economic profit, or personal interest. To invite others to a dugnad places an obligation on the host to make sure that the dugnad criteria are fulfilled. The project should form part of a system of reciprocity which promotes communal solidarity and the common good. No requirement of special skills or potential for harm should prevent anybody from taking part. In this way, a dugnad project should act as an incarnation of citizenship and the ethics of belonging to a community. 


\section{Biobank participation}

Does the analogy of dugnad serve as a means to achieving a more adequate description of what participation in medical research in general and biobank research in particular entails? We take the HUNT study as a starting point for a general discussion of the relevance and implications of introducing the dugnad analogy to this field.

In total, 110,000 people in the Norwegian county of Nord-Trøndelag have been or will be invited to take part in HUNT3, the third round of HUNT studies taking place in the period 2006-2008. The HUNT cohort consists of a major part of the population of the county of Nord-Trøndelag. All citizens aged 13 or older have been invited to participate in HUNT by completing a questionnaire on health-related issues, undergoing optional medical tests, and (from HUNT2 onward) allowing a blood sample to be taken and included in the HUNT biobank.

In the previous HUNT study in the 1980s (HUNT1) and the HUNT2 study in the 1990s, the participation rates were $88.1 \%$ and $71.3 \%$ of the adult population, respectively (Holmen et al. 2004). The participation rate in HUNT3 is expected to be $c .60 \%$. Even if the participation rate is declining, these figures show that the majority of the people of Nord-Trøndelag not only support the research project but actually decide to take part. Steinar Krokstad, vice-chairman of the HUNT research centre, explains the willingness to participate in this way: «In Nord-Trøndelag, there is traditionally a strong belief in the power of cooperation and collective action. Cooperation has been strong, and when HUNT has invited people to participate in a health dugnad, they have shown up.» (Krokstad 2004)

Krokstad goes on to state that «modern society is characterised by the disintegration of the community», and that the HUNT dugnad will contribute to counteract this development in a threefold way. Firstly, HUNT by itself promotes the dugnad spirit in its participants, secondly, HUNT might be able to detect adverse health consequences of societal disintegration, and thirdly, HUNT promotes collective action for improved public health:

The people of Nord-Trøndelag can be the first to benefit from new ways to better public health, through knowledge that can be communicated to the whole world in international journals. [...] Norway has developed from a poor country with a lot of poor health and living conditions to be a country with the best public health in the world. The Universal Health Insurance and the social security net that protects us from poverty are based on the old principles of equality, liberty and fraternity. And these institutions still contribute to good public health. (Krokstad 2004)

The fall in participation rate between HUNT1, HUNT2 and HUNT3 indicates that the dugnad spirit has declined in Nord-Trøndelag. In this article we will not speculate on why this is so, but rather note that in HUNT (as in many other projects worldwide) there is a need for normative recruitment 
in order to secure a high attendance rate. The crucial question then becomes whether normative recruitment is always wrong and incompatible with the ideals of modern research ethics, or whether in a case like HUNT it is legitimate.

In a focus group study with HUNT researchers we asked whether biobank participants should have priority in receiving public health care over those who do not participate. ${ }^{8}$ No one thought this should be the case, but one researcher expressed the general sentiment towards those who do not participate rather succinctly by remarking «they should maybe search their consciences». Another researcher elaborated on this remark when asked whether biobank participation should be a legal duty:

\footnotetext{
I think that everybody has a moral duty to participate. And I think that Norwegians in general see it this way, and that the participation rate in HUNT shows that the people in Nord-Trøndelag see it this way. To participate should not be a legal duty, since it interferes with the private sphere. But I think there are few people who would oppose participation in HUNT if the collective goods it entails are clearly stated, and that we all agree that such a study should be a part of our collective efforts to improve our health service.
}

In this respect, the concept of dugnad has the potential both to clarify and obscure the balancing of privacy rights, civic duties and legal duties. We will show how by identifying the determining factors present in both the HUNT and MIDIA $^{9}$ research projects.

\section{Is HUNT a dugnad?}

The word dugnad does not explicitly appear in the official information material for HUNT. However, the dugnad spirit is evoked in the way that HUNT motivates people to participate, thus this analogy seems to be clearly warranted. In an information folder for HUNT3 we read:

\footnotetext{
Something very important for public health is happening in our county right now! You can contribute to vital research and increased knowledge about diseases which are of concern to us all. [...] We have every reason to be proud of HUNT. HUNT is the largest health survey of the world. [...] Please participate! Let's give each other an hour for better public health!
}

The request to give «each other an hour for better public health» refers to the time it takes to complete the HUNT questionnaire and give a blood sample. ${ }^{10}$ From this perspective, the participants contribute mainly by giving their time. The risk of participation is conceived of as negligible, and the participants are not asked to make huge sacrifices: they will leave the research centre in the same shape as before - except without a few centilitres of blood. 
Thus, the participants are primarily asked to do a little unpaid work: to show up and take time to answer questions, and allow for health data and a blood sample to be obtained. It is work in the sense that participation is not for personal health purposes: no individual feedback is provided on the basis of biobank research findings. When the participants have done their share, the job is finished. In this way, participants are considered to be contributing as citizens rather than as patients. Moreover, the work is unpaid in the sense that except for the free brief health check, there is no compensation given to participants.

HUNT could be said to be a dugnad in the modern sense of being a gathering of people to do unpaid work for some kind of common good. Of course, both the "gathering» and the «common good» might be said to be quite abstract in this case: like Wikipedia contributors, the participants do not actually gather at one place. For the participants, the common good is also vaguely conceivable rather than directly perceivable. Moreover, the participants are, as we will see, a little uncomfortable regarding their contribution as «work». Given the fact that the free personal health check offered by HUNT motivates some people to take part makes it contestable to call their participation «work», and even debateable if the participation is wholly «unpaid». Moreover, the participants in both a traditional and a modern dugnad enjoy benefits such as good food and beverages, but these kinds of benefits are not of the same personal nature as an individual health check.

HUNT could also be said to be a dugnad in the traditional sense of offering an intergenerational system of reciprocation between equal parties: no HUNT participant is more important than another, everybody contributes in more or less the same way, and everybody can expect the same kind of possible benefit from the research from an intergenerational perspective. This emphasises how both the HUNT study and the traditional dugnad can be viewed as a kind of insurance institution. In this respect, however, a major disparity would be that while stepping outside the traditional dugnad institution might have implied grave and direct social and economic consequences for a farmer in the 19th century, a person declining to take part in the HUNT study today should, as a matter of principle, expect no personal consequences from his or her decision when it comes to the future provision of health care. It is an important part of the HUNT recruitment policy, however, to appeal to the direct personal gain from having a free health check. In this way, participation is not purely altruistic - there is «something in it for me», which makes it meet a basic criterion of the dugnad design. 


\section{The opinion of biobank participants}

In the focus group study with HUNT participants, we asked whether biobank participation should be considered a legal obligation. ${ }^{11}$ Like the researchers, none of the focus group participants thought this wholly appropriate. Biobank research is conceived of as interfering with the private, or autonomous, sphere of the citizen. To protect such a sphere is viewed as fundamental to the Norwegian constitutional State, separating it from totalitarian regimes. The ability to excuse oneself from participation in HUNT based on religious views and views of bodily integrity is seen as important. Making the right to health care somehow dependent on one's participation in medical research was definitely not endorsed by the focus group participants, because of the observed right not to participate, as well as the fact that everyone takes part in financing the universal Norwegian health service by paying taxes.

The general line of thought, however, echoing the opinions of HUNT researchers, is that even though a legal duty would be wrong, people should feel a certain moral duty to take part in HUNT. Everybody should participate in HUNT, one man said, because "the ideal is of course that everybody should contribute to the community, but then again you have the right to decide when it comes to your personal stuff.» Generally, the interests of the State and its citizens are perceived as identical when it comes to the aims of biobank research: it is in everybody's interest to promote health by improving our ability to prevent and treat diseases.

Biobank research is perceived as a low-risk way of participating in beneficial medical research. The participants evidently have quite vague ideas of the potential embodied in the research: perhaps their children or future generations will benefit from HUNT. ${ }^{12}$ The motivation for their participation is altruistic and patriotic: They are proud to take part in a study for the possible benefit of the whole world, and take pride in the fact that such an altruistic project has been initiated by, and is being accomplished with the massive participation of, people from their own county (Antonsen 2005: 104).

\section{The importance of solidarity}

The main elements in HUNT that constitute a dugnad can easily be identified. Even though it is different from a traditional dugnad in some respects, it seems fair to say that HUNT is a dugnad, or at least it is a project in the dugnad spirit. Does it or could it, however, have elements that are clearly incompatible with being a dugnad?

The participants in our study were not asked to relate the concept of $d u g$ nad to biobank participation, but their answers concerning the importance 
of taking part point to elements of the concept of the dugnad: participation should not be a legal duty, nor should the question of participation be entirely neutral in moral terms; participation should be morally laudable as a positive voluntary commitment to contribute to the common good.

On the other hand, the participants saw commercialisation of biobank research as a possible threat to this aspect of the endeavour. To make medicine for the rich rather than the needy, and thereby to profit from the voluntary contributions of the inhabitants of Nord-Trøndelag, would be at odds with the nature of the biobank project as they perceived it. This shows that solidarity is an essential motive for participation in biobank research, and that commercialisation might frustrate this motivation and fundamentally alter the nature of the enterprise. This can be illustrated by comparing the HUNT project to the story of the dugnad in Valdres involving the building of a mountain hotel. With their goal of private profit, the Valdres hotel entrepreneurs violated the dugnad principles of reciprocity and solidarity, and therefore their framing of the project as a dugnad was illegitimate. In the eyes of participants, taking advantage of the potentially commercial aspect of biobanking would transform the project in an essential way: the project would be about non-reciprocated private profit rather than the mutual or common good, thereby exploiting participants if involvement was to be presented as a dugnad.

Interestingly, the principles that HUNT participants regarded as both essential to the legitimacy of the study and as threatened by commercialisation, are the same as the principles which the HUNT project has to adhere to in order to qualify as a dugnad: HUNT must be in pursuit of the common good in solidarity, from which all participants and their descendants equally benefit. It is, however, important to note that commercialisation per se is fully compatible with these principles, as long as commercial research is incorporated into the system of research ethics committees, ${ }^{13}$ and if it only accelerates certain fields of research in addition to, rather than instead of, publicly funded research for the common good.

\section{Normative recruitment and the Helsinki Declaration}

According to the 2004 Helsinki Declaration ${ }^{14}(\$ 5)$, the interests of the individual should always precede those of the society: «The subject should be informed of the right to abstain from participation in the study or to withdraw consent to participate at any time without reappraisal.»(\$10), and in $\$ 11$ it is stated: «When obtaining informed consent for the research project the physician should be particularly cautious if the subject is in a dependent relationship with the physician or may consent under duress.» Taken together, these paragraphs seem to imply that all recruitment to medical 
research must be normatively neutral: in general one should never argue that a person ought to forsake his or her own interests to participate in the interests of future health care (\$5), and in particular that he or she has a particular obligation to participate, given the relationship of dependence between the person and the provision of health care $(\$ 10-11) .{ }^{15}$ As we have seen, participants and researchers in HUNT firmly reject the idea of refusing non-participants the same rights to future health care as the participants; Is the moral pressure of the dugnad model exactly what these paragraphs are meant to exclude?

The principles of the Helsinki Declaration are meant both to secure the autonomy of potential participants and to protect them from harm. As touched upon above, the nature of biobank research makes the risk for physical harm negligible. The most important concern is thus to guarantee that no one is deceived or coerced into taking part. The crucial question, then, is whether and when normative recruitment implies the deception or coercion of individuals, which would thereby make it illegitimate. Is it possible to defend an ideal of free and informed decisions by all potential biobank participants as to whether or not to take part, if participation in the research project in question is presented as morally laudable or obligatory? Is it legitimate to appeal to the dugnad spirit in recruiting people to HUNT?

The Helsinki Declaration, John Harris and the HUNT participants all agree that a fundamental principle of medical research is that participation is voluntary, and that no one is invited to take part in research when there is an unfavourable risk-benefit ratio. Given this, one starting point would be to say that any medical research should identify the risks to and the interests of the participants and society in the project, in order to be able to state these dangers and interests clearly in the invitation to take part. It would then be unethical for researchers to invite individuals to take part in a study in which they did not think that those invited really should take part. In other words, the researchers who invite people to take part in a project not only generally have an interest in a high participation rate, but it is more precise to say that also the researchers always should have an interest in a high participation rate. Researchers should believe that it is in everybody's interest for everyone who is invited to choose to take part.

The dugnad analogy is demanding in its aim for a collective consensus on the need for and legitimacy of the research, and the moral duty to take part. The crucial point, however, is that this puts a normative pressure on the invited participants and the project designers alike. To present a medical research project as a dugnad should in general be done with extreme caution, as it is a strong rhetorical device that might blur reflections on personal risk, as well as the nature of the common good involved. To put a normative pressure on the participants in this way thus puts a huge normative pressure on the research institution and the relevant governmental bodies. 
They have to ensure and be sure that a project meets the criteria of being a dugnad. Only if these criteria are met is the invitation to take part in a research dugnad valid, and only if these criteria are met is this use of normative recruitment legitimate.

Given a transparent and informative process of voluntary recruitment, the research institutions are dependent on the trust of potential participants. This makes an appeal to the dugnad spirit a double-edged sword: if the research projects are conceived by participants to rightly deserve the dugnad label, it might improve the participation rate, but if the project in question is seen as not deserving the dugnad label it might mean that the participants lose their trust in the project altogether. The fear that this might happen partly explains the reluctance of research institutes in Norway to invoke the dugnad spirit explicitly in their official documents and invitations. ${ }^{16}$

Rather than being a simple way to recruit people for research, normative recruitment is a demanding way to recruit volunteers for a transparent project dependent on trust. Normative recruitment might nevertheless be a way to make clear the mutual duties of a research-based health service, and its potential patients and research participants. This might promote rather than hamper the ability of participants to make an autonomous decision as to whether or not they should take part, as prescribed by the Helsinki Declaration. Normatively neutral recruitment might downplay ethical aspects of the research, such as urgency and justice, because people are simply invited in a neutral way and may participate if they wish. No one has said that they should take part, so the motivation to autonomously question the ethical aspects of the relevant research is significantly lower.

\section{When normative recruitment is not justified}

Appeals to participate in a dugnad and the dugnad spirit need to be justified in the general design of a biobank such as HUNT. Appeals to participate in a dugnad also need to be justified in specific projects using biobank material, or in targeted biobank projects. How does a specific biobank research project appear, if normative recruitment is not justified? The Norwegian MIDIA research project on the environmental causes of type 1 diabetes is illustrative in this respect.

The starting point for the MIDIA project was that people with a special genotype have a higher risk of developing type 1 diabetes. Approximately $2 \%$ of the Norwegian population is in this group. In MIDIA, pregnant women were invited to let their future newborn children take the genetic test for type 1 diabetes. Subsequently, approximately 2000 «high risk» children were expected to be identified. These children would then be followed by researchers for $c .15$ years. Their mothers and fathers were asked to deli- 
ver faecal samples every month until the baby was 3 years old. In addition, blood samples and questionnaires were to be delivered four times during the first year and then once a year until the child reached the age of 15 years (Rønningen et al. 2007: 2405).

Although MIDIA was huge, prestigious, with substantial national governmental funding, and of international interest, it was found to violate the Norwegian Biotechnology Act. After having identified c.1000 babies at risk, MIDIA came to be seen as highly controversial by Norwegians. Parents who were warned of an increased risk for their children based on the predictive genetic test expressed fear and anger about having this information. From their perspective, the fantastic experience of having a baby was tainted by the focus on a possible future disease, without any ability to prevent it (Anonymous 2007: 1824). The Norwegian Biotechnology Advisory Board considered the project in relation to the Biotechnology Act. They concluded that the predictive genetic testing of children for diseases that cannot be prevented is forbidden by Norwegian law (Foss 2007).

However, whether MIDIA was in accordance with Norwegian law or not, is not the main point here. The importance lies in the incident as an example of a research project putting substantial burdens on the shoulders of the participant. In its invitation letter, MIDIA used a language of normative recruitment: «Congratulations on the birth of a newborn citizen! [...] It may seem early, but we would still like to invite you and your little newborn citizen to make your first benevolent contribution to society.» ${ }^{17}$ The invitation letter refers to citizenship, to the relationship between a citizen and society, and to benevolent contributions and the common good. The baby is referred to not as an individual but as a citizen, with the expression of sentiments and ideas about what good citizenship and civic duties amount to. As we have already made clear in this article, our argument is not that this is principally wrong. Rather, we argue that the legitimacy of this kind of normative recruitment presupposes certain kinds of research designs - such as fulfilling the criteria for being a dugnad.

Our question is then: If the MIDIA project was more or less presented as a dugnad - was it in accordance with a «dugnad design»? MIDIA revealed the results of babies' predictive genetic tests to their parents. As there are no preventive measures available for type 1 diabetes, the information caused psychological stress and worry for some parents. Some parents were given information that they later wished they had rather stayed ignorant of. Thus, the right not to know was neglected. The need to provide faecal samples, blood tests and answer questionnaires on a continuous basis added to participants' inconvenience. For one 15-year-old MIDIA participant, there was a $93 \%$ probability that she would not develop diabetes, and she would have to live with the risk awareness for the rest of her life without being part of any research project. 
In sum, it is easy to conclude that MIDIA did not have a dugnad design. The inconvenience was substantive rather than negligible. It is not in accordance with dugnad criteria to subject invited participants to severe inconvenience or risk. In this respect, the empirical factors of the study design are crucial for assessing the ethical question of the legitimacy of normative recruitment. In the MIDIA case, implicit references to civic duties and explicit references to citizenship and contributions to society functioned as an illegitimate rhetorical device.

\section{Accounts of duties}

The aim of an account of duties to participate in medical research is to provide a middle ground between asserting a general duty to take part in medical research, and a general principle of normatively neutral recruitment of participants - which implies that the potential participant should not feel any obligation to take part. While a general duty is argued for on the basis of a relationship of mutual duties between the health care provider and recipient, normatively neutral recruitment is argued for on the basis of fundamental principles of medical research ethics.

Daniel Callahan, as we have shown, is dismissive of the argument that we have a duty to conduct and participate in medical research in order to benefit future generations, in the same way that preceding generations have made our health care system possible. It follows, then, that he must hold either that there never really was such a social contract between generations, or that we stand in a radically different relation to our descendants concerning medical research than did our forebears. Both of these substantial claims are rather controversial, and, as we have seen, have not been met with approval among HUNT participants.

What seems to be more promising than generating controversy over a general duty to participate in medical research is developing as accurately as possible Rhodes and Harris's sense of a prima facie moral obligation to take part in medical research. Harris argued that people who do not participate in research are freeriders who opt for the benefits from medical research without making a contribution. Contrary to Harris's argument, the division of labour in modern society is a form of an organised system of legitimate freeriders. This argument can be turned on its head, however. Considerations of justice might be deemed relevant for individuals specifically called upon to participate in this division of labour, as in the HUNT case. Infinite duties are then transformed into socially finite and perfect ones if part of a well-organised and limited system of medical research, such as the one described in Rhodes's «novel proposal». 
However, rather than just asserting a general duty to participate in such a system of research, the dugnad analogy illustrates the need for a description of how such a duty presupposes specific conditions regarding the research design. The research design has to meet conditions concerning both the nature of the involvement of the individual in terms of beneficence and non-maleficence. Furthermore, it also has to make clear its contribution to the creation of the common good. The dugnad model presupposes a sensitivity and openness for debate on whether and how the research design actually promotes the creation of the common good, as conceived in the community in question. Pace the purely apolitical accounts of duties of research participation promoted by Harris and Rhodes, this points to a justification of normative recruitment which is sensitive to politics.

\section{Citizenship and the ethics of belonging}

Our discussion of the HUNT case as analogous to a dugnad has shown that talking about moral obligations to participate in medical research essentially involves detailed descriptions of the research in question, including aspects such as its organisation, its aims, its beneficiaries, its potential, its urgency, and of belonging and membership. The discussion of whether potential participants have a perfect or an imperfect duty to participate in medical research on the basis of a limited description of the research involved is not very promising. It is difficult to make a plausible case by asserting an individual's general duty to participate. A limited description of the relevant research also does a poor job of describing the moral motivation to take part in specific research projects.

A nuanced and situated description of the normative basis for individual participation in collective projects is vital to the discussion of moral motivations and obligations in this field. The dugnad analogy introduced in the HUNT case shows this in an illustrative way. People take part in dugnad not just as individuals but as members of a community. Their motivation is neither purely altruistic nor purely egoistic. It is more about a sense of belonging on different levels: We belong to a society where health is a common good. We belong to a patient group or a local community that may make a difference regarding health for future generations. In this way we are members of communities that involve a kind of civic duty to participate. As members, or citizens, the right thing to do is to participate. In this respect it might be said to be a kind of patriotic act, in Charles Taylor's sense, because it

[...] transcends egoism in the sense that people are really attached to the common good, to general liberty. But it is quite unlike the apolitical attachment to universal principle that the stoics advocated or that is central to modern ethics of rule by law. 
The difference is that patriotism is based on identification with others in a particular common enterprise. [...] Patriotism is somewhere between friendship or family feeling, on one side, and altruistic dedication on the other. (Taylor 1995: 188)

In this way, patriotism can be viewed as highly relevant for participation in medical research.

Patriotism and dugnad thus go hand in hand. This could imply a «politisation» of science, yet there is nothing wrong with that. Rather, the opposite is true: when medical research is "politicised» through concepts such as citizenship, community, belonging, and patriotism, the question is also raised regarding the direction and development the relevant community and research project should be headed towards. Opposition to biobank research is typically a political one, like the critique of biobank research representing a "geneticisation» of medical research - shifting the focus away from social inequality and health to a focus on genetic explanations. Such opposition does not lead to less civic engagement, but rather more. This challenges research communities for certain research projects to be able to defend normative recruitment, and to make an appeal to the common good.

\section{Conclusions}

The dugnad analogy offers the opportunity to understand how a specific research project should be designed to support an asserted moral obligation to take part. Ignorable risk, ignorable inconvenience and a common good that addresses each person as a member of a community rather than just as an individual, are core elements in the dugnad design. Normative recruitment should be seen as legitimate in these cases. That the criteria essential to the legitimacy of HUNT coincides with the criteria to qualify as a dugnad shows the potential suitability of such an approach. ${ }^{18}$

Normative recruitment is a powerful rhetorical device. Medical research is not in general a dugnad, and normative recruitment is not in general legitimate. An important message of this article is to suggest that as early as possible in the design phase of a project, researchers should reflect on the relationship of their project to the community of potential participants and to the common good. This will imply a "politicisation» of medical researchers - but that would be for the better. Ethics separated from politics is anaemic. Aanaemic ethics for biobanking benefits neither biobank research nor the participants. 


\section{Acknowledgements}

The authors would like to thank Nancy Bazilchuk, Bjørn Hofmann, Bjørn Myskja, Rune Nydal, John-Arne Skolbekken, Jan-Helge Solbakk, and two anonymous reviewers from the Nordic Journal of Applied Ethics for their valuable comments on and linguistic improvements to this article. All translations from Norwegian have been made by Lars Øystein Ursin and Berge Solberg.

\section{Notes}

1 Cf. Brassington 2007, Beauchamp 2005; London 2005; McGuire \& McCulloch 2005; Sharp \& Yarborough 2005; Sharpsay \& Pimple 2007; Wachbroit \& Wasserman 2005.

2 In order to show that non-participants are freeriders, Harris needs to show that in declining to take part, non-participants actually hamper the research in a decisive way. Chan and Harris compare non-participation in research with non-participation in immunisation (Chan \& Harris 2008: 4). Their analogy is flawed, however, since the non-participation of only some individuals disrupts herd immunity but not research opportunity. We will suggest a better way to view how the principle of fairness relates to biobank participation later in this chapter.

3 Chan and Harris also seem to tend toward viewing the obligation in question as imperfect: «How much money 'should' you give to charity or to good causes, how hard should you work to discharge your obligation to your employer? The absence of a definable answer to this question does not make giving to charity or doing a fair day's work any less of a moral good, neither does the problem of how much research is enough invalidate the obligation to pursue it.» (Chan \& Harris 2008: 10). Both here, and in their blunt statement «there is an obligation to support all sorts of public goods» (Chan \& Harris 2008: 5), it is hard to make sense of their view if the notion of obligation implied is the perfect one.

4 HUNT is a Norwegian acronym for the «Health Study of Nord-Trøndelag» (Helseundersøkelsen i Nord-Trøndelag)

5 See, for instance, Gunnar Bovim in 'Sikkert som biobanken?' in Adresseavisen, 20 July 2001, and in 'Har overtatt verdens største helseundersøkelse' in Universitetsavisa, No. 1, 2001, p. 12, Steinar Krokstad in 'Ønsker flere «pasienter» til Hunt 3' in Namdalsavisa 12 May 2008, and in 'HUNT, nordtrønderne og helsedugnaden' in Trønderavisa 18 September 2004, and Stig Slørdahl in 'Hard trening mest effektivt', in Levanger-avisa, 15 December 2005, and in 'Store innskudd i ny biobank' in Universitetsavisa, 15 February 2007

6 Wikipedia is available online at http://en.wikipedia.org/wiki/Main_Page It is the largest free encyclopaedia in the world, and invites readers to contribute and edit existing entries.

7 For a discussion of relevant aspects of the deCode project, see Palsson \& Hardardottir 2002

8 The focus group participants comprised of people who had given their consent to participate in the HUNT biobank (5 groups), former participants who had withdrawn their consent to take part in the biobank (3 groups), and researchers who were involved in or had an interest in HUNT (5 groups). The groups were recruited with the help of HUNT biobank. The focus group sessions took place in the autumn of 
2004 and the spring of 2005. The five discussion themes of the focus groups were: 1 . The use (and abuse) of the biobank material; 2 . Their own decision for giving consent/not giving consent, and the appropriateness of different kinds of consent; 3 . Duty versus autonomy in biobank research participation; 4 . The ethical and practical consequences of conducting genetic research versus other kinds of medical research in HUNT; and 5. Commercialisation of the biobank research. The focus group participants discussed (rather freely) questions concerning the use of general consent concerning biobank participation, the adequacy of a putative duty to take part, the ethical consequences of commercial use of HUNT biobank material, and their general hopes and fears concerning the biobank research carried out by HUNT. The focus group study was designed by two ethicists (Berge Solberg and Lars Øystein Ursin) and a social scientist (John Arne Skolbekken), who also was the group moderator. For a presentation of further aspects of the focus group study, see Skolbekken et al. (2005).

9 MIDIA is a Norwegian abbreviation for «Environmental causes of type 1 diabetes» (Miljøårsaker til type 1 diabetes).

10 Cf. Collins (of UK Biobank) in Petersen (2006: 491).

11 Cf. Skolbekken et al. (2005).

12 Cf. Skolbekken et al. (2005: 340).

13 Cf. also Kettis-Lindblad (2005).

14 World Medical Association Declaration of Helsinki: Ethical Principles for Medical Research Involving Human Subjects. Available at www.wma.net/e/policy/b3.htm Accessed 2008-09-24

15 Ibid.

16 Similarly, the Governmental Regional Research Ethics Committees does not readily approve of the use of normative words such as dugnad in research recruitment.

17 Cf. www.fhi.no/dav/D651 389BCD.pdf Accessed August 2008.

18 The dugnad concept might be said to be more than just a model or an analogy - it might be argued that the HUNT study is indeed a dugnad, and not just possible to view as a dugnad.

\section{Literature}

Antonsen, S. (2005) Motivasjon for å delta i helseundersøkelser. Norsk Epidemiologi, 15 (1), pp. 99-109.

Beauchamp, T. (2005) How not to rethink research ethics. The American Journal of Bioethics, 5 (1), pp. 31-33.

Brassington, I. (2007) John Harris' argument for a duty to research. Bioethics, 21 (3), pp. 160-168.

Callahan, D. (2003) What price better health? Hazards of the research imperative. Berkeley: University of California Press.

Chan, S. \& Harris, J. (2008) Free riders and pious sons - Why science research remains obligatory. Bioethics, epub ahead of print, doi 10.1111/j.14678519.2008.00 648.x.

Foss, G. (2007) Gentesting av barn i MIDIA-prosjektet. Genialt, 3, pp. 12-15.

Harris, J. (2005) Scientific research is a moral duty. Journal of Medical Ethics, 31, pp. 242-248. 
Holmen, J., Kjelsaas, M. B., Krüger, Ø., Ellekjær, H., Bratberg, G., Holmen, T. L., Midthjell, K., Stavnås, P. A. \& Krogstad, S. (2004) Befolkningens holdninger til genetisk epidemiologi illustrert ved spørsmål om fornyet samtykke til 61.246 personer - Helseundersøkelsen i Nord-Trøndelag (HUNT). Norsk Epidemiologi, 14 (1), pp. 27-31.

Kettis-Lindblad, Å., Ring, L., Viberth, E. \& Hansson, M. (2005) Genetic research and donation of tissue samples to biobanks. What do potential sample donors in the Swedish general public think? European Journal of Public Health, 16 (4), pp. 433-440.

Klepp, A. (1982) Reciprocity and integration into a market economy: An attempt at explaining varying formalization of the «dugnad» in pre-industrial society. Ethnologia Scandinavica, pp. 85-93.

Klepp, A. (2001) From neighbourly duty to national rhetoric, Ethnologia Scandinavica, 31, pp. 82-98.

Krokstad, S. (2004) HUNT, nordtrønderne og helsedugnaden. Trønderavisa, 18. september 2004.

London, A. (2005) Does research ethics rest on a mistake? The common good, reasonable risk and social justice. The American Journal of Bioethics, 5 (1), pp. 37-39.

McGuire, A. \& McCulloch, L. (2005) Respect as an organizing normative category for research ethics. The American Journal of Bioethics, 5 (1), W1-2.

Anonymous (2007) Gentesting - en belastning for pårørende. Tidsskrift for Den norske loegeforening, 13 (127), p. 1824.

Norddølum, H. (1976) Dugnaden i det førindustrielle samfunn. Dugnad, 2, pp. 6580 .

Norddølum, H. (1980) The «dugnad» in the pre-industrial peasant community. An attempt at an explanation. Ethnologia Scandinavica, 1980, pp. 102-112.

Palsson, G. \& Hardardottir, K. (2002) For whom the cell tolls. Current Anthropo$\log y, 43$ (2), pp. 271-301

Petersen, A. (2006) The genetic conception of health: Is it as radical as claimed? Health, 10 (4), pp. 481-500.

Rhodes, R. (2005) Rethinking research ethics. The American Journal of Bioethics, 5 (1), pp. 7-28.

Rønningen, K., Stene, L., Rasmussen, T., Wetlesen, T. \& Magnus, P. (2007) Miljøårsaker til type 1-diabetes. Tidsskrift for Den norske loegeforening, 127 (18), pp. 2405-2408.

Sharp, R. \& Yarborough, M. (2005) Additional thoughts on rethinking research ethics. The American Journal of Bioethics, 5 (1), pp. 40-41.

Sharpsay, S. \& Pimple, K. (2007) Participation in biomedical research is an imperfect moral duty: A response to John Harris. Journal of Medical Ethics, 33 (7), pp. 414-417.

Skolbekken, J. A, Ursin, L., Solberg, B., Christensen, E. \& Ytterhus, B. (2005) Not worth the paper it's written on? Informed consent and biobank research in a Norwegian context. Critical Public Health, 15 (4), pp. 335-348.

Taylor, C. (1995) Cross-purposes - the liberal-communitarian debate. In Philosophical arguments, C. Taylor, pp.181-203 Cambridge: Harvard University Press.

Wachbroit, R. \& Wasserman, D. (2005) Research participation: Are we subject to a duty? The American Journal of Bioethics, 5 (1), pp. 48-49.

Østberg, K. (1926) Dugnad. Norske Folkeskrifter, 71. 